\title{
ABORDAGEM MULTIDISCIPLINAR PARA INDICAR AS PROVÁVEIS AMEAÇAS À SAÚDE E À QUALIDADE DE VIDA DA COMUNIDADE CAIÇARA ILHA DIANA
}

\section{MULTIDISCIPLINARY APPROACH TO INDICATE PROBLEMS OF HEALTH AND LIFE QUALITY OF THE CAIÇARA COMUNITY "ILHA DIANA"}

\author{
Larissa Felicidade Demarco \\ Pesquisadora Msc, Instituto de Pesquisas Tecnológicas do Estado de São Paulo \\ larissaf@ipt.br \\ Leonardo Silveira Takase \\ Oceanógrafo, Instituto Oceanográfico da Universidade de São Paulo \\ leonardo.takase@gmail.com \\ Marcos Jorgino Blanco \\ Pesquisador MSc, Instituto de Pesquisas Tecnológicas do Estado de São Paulo \\ marib@ipt.br \\ Luiza de Araújo João Sobrinho \\ estudante, Instituto do Mar da Universidade Federal de São Paulo \\ luiza.ajs9@gmail.com
}

\begin{abstract}
RESUMO
Este artigo apresenta parte do desenvolvimento e resultados do projeto social fomentado pela Fundação de Apoio ao Instituto de Pesquisas Tecnológicas. O projeto teve duração de um ano e foi desenvolvido em conjunto com duas empresas juniores, IO Jr (Instituto Oceanográfico - Universidade de São Paulo) e IMar Jr (Instituto do Mar - Universidade Federal de São Paulo), ambas parceiras do referido projeto. O bairro de Ilha Diana, área em que o estudo foi realizado, está localizado em uma porção do Sistema Estuarino de Santos, onde opera o maior porto da América Latina, o Porto de Santos. Com objetivo de realizar uma análise inovadora para identificar as ameaças à saúde e à qualidade de vida a qual a população da comunidade está exposta, a metodologia desenvolvida contou com uma abordagem multidisciplinar, a partir da avaliação de parâmetros ambientais em amostras do solo da comunidade, de organismos, de sedimento de fundo e de água do Rio Diana e de parâmetros sociais como Saúde, Educação, Infraestrutura, EconômicoFinanceiro, Saneamento, Sensação de Pertencimento, Transporte e Comunicação. A integração dos dados foi realizada por meio da lógica Fuzzy. Os resultados das análises ambientais indicaram a necessidade constante de acompanhamento destas e dos riscos agregados, sendo necessária a manutenção de estudos ambientais sistemáticos e duradouros, bem como a promoção da educação ambiental para os moradores da comunidade, a fim de se obter uma série histórica que poderá apresentar a diminuição de tais índices, fruto das ações sociais implementadas. A partir dos parâmetros sociais avaliados foi possível perceber que a principal ameaça à qualidade de vida da população com relação à saúde é a falta de saneamento básico.
\end{abstract}

Palavras-chave: Determinantes Socioambientais. Lógica Fuzzy. Variáveis Ambientais. Variáveis Sociais.

Recebido em: 19/07/2019

Aceito para publicação em: 04/03/2020 


\begin{abstract}
The present's article shows part of the development and results of the social project promoted by the Support Foundation to the Institute of Technological Research (FIPT). The project was developed together with two junior companies, IO Jr (Oceanographic Institute - University of São Paulo) and IMar Jr (Instituto do Mar - Federal University of São Paulo). The Ilha Diana community is located in a portion of the Estuarine System of Santos where is located the largest port in Latin America: Santos Harbor. In order to perform an innovative analysis to identify the threats to health and quality of life to which the community population is exposed, the methodology developed had a multidisciplinary approach based on the evaluation of environmental and social parameters. The environmental parameters were composed by soil samples, organisms, marine sediment and water from the Diana River. The social parameters were composed by information provide from the Health, Education, Infrastructure, Economic-Financial, Sanitation, Sense of Belonging, Transportation and Communication of the community. Data integration was performed using Fuzzy logic. The results of environmental analyses indicated the constant need for monitoring these and aggregate risks, requiring the maintenance of systematic and lasting environmental studies, as well as the promotion of environmental education for residents community. From the social parameters evaluated it was possible to realize that the main threat to the quality of life of the population in relation to health is the lack of basic sanitation.
\end{abstract}

Key-words: Social parameters. Environmental parameters. Fuzzy Logic.

\title{
INTRODUÇÃO
}

Este trabalho compreende a descrição de parte dos resultados obtidos durante o desenvolvimento do projeto social fomentado pela Fundação de Apoio ao Instituto de Pesquisas Tecnológicas (FIPT) por meio de seu "Programa de Investimento Social Privado" ${ }^{2}$. O projeto consistiu na avaliação socioambiental e proposição de medidas mitigadoras para a comunidade caiçara do bairro llha Diana - Santos/SP e foi desenvolvido por pesquisadores do Instituto de Pesquisas Tecnológicas do Estado de São Paulo (IPT) em parceria com os alunos de duas empresas juniores: a IMar Jr (Universidade Federal de São Paulo, Instituto do Mar - Santos/SP) e a IO Jr (Universidade de São Paulo, Instituto Oceanográfico - São Paulo/SP).

O Ilha Diana é um bairro na área continental do município de Santos, localizado na confluência do rio Diana com o canal de Bertioga, a cerca de $8 \mathrm{~km}$ do Porto de Santos, próximo a Base Aérea de Santos e ao distrito de Vicente de Carvalho $(1,5 \mathrm{~km})$, no Guarujá. Possui uma área de aproximadamente $330.000 \mathrm{~m}^{2}$ e cerca de 210 moradores distribuídos em 60 famílias e 61 casas (Figura 1).

O acesso ao bairro se dá apenas por barco coletivo, que sai do centro de Santos, ou por embarcações de uso pessoal de pequeno porte. Além disso, possui equipamentos de infraestrutura urbana e oferta de serviços básicos como coleta de resíduos sólidos, posto de saúde, creche (para crianças de até 06 anos) e uma escola de primeiro a quinto ano (até 10 anos), além de uma brinquedoteca. A responsável pela administração da llha é a própria prefeitura municipal de Santos.

A comunidade do llha Diana é formada por pescadores artesanais e é reconhecida pela manutenção do modo de vida caiçara, onde os traços dessa cultura ainda podem ser observados nas tradições, técnicas e artefatos utilizados na pesca (TORRES et al., 2016). Apesar das interferências urbano-industriais que vem sofrendo ao longo das últimas décadas, a comunidade mantém uma população bastante tradicional de pescadores, não tendo sofrido, até o momento, um processo de favelização, se comparada a outras comunidades tradicionais da região como identifica Romani (2010).

\footnotetext{
${ }^{2}$ Informações sobre o Programa de Investimento Social Privado estão disponíveis em: https://fipt.org.br/\# e por meio do acesso aos editais anteriores https://fipt.org.br/chamadas-e-editais/
} 
Figura 1 - Mapa de localização do bairro Ilha Diana, Santos-SP. Extraído de Demarco et. al (2018).

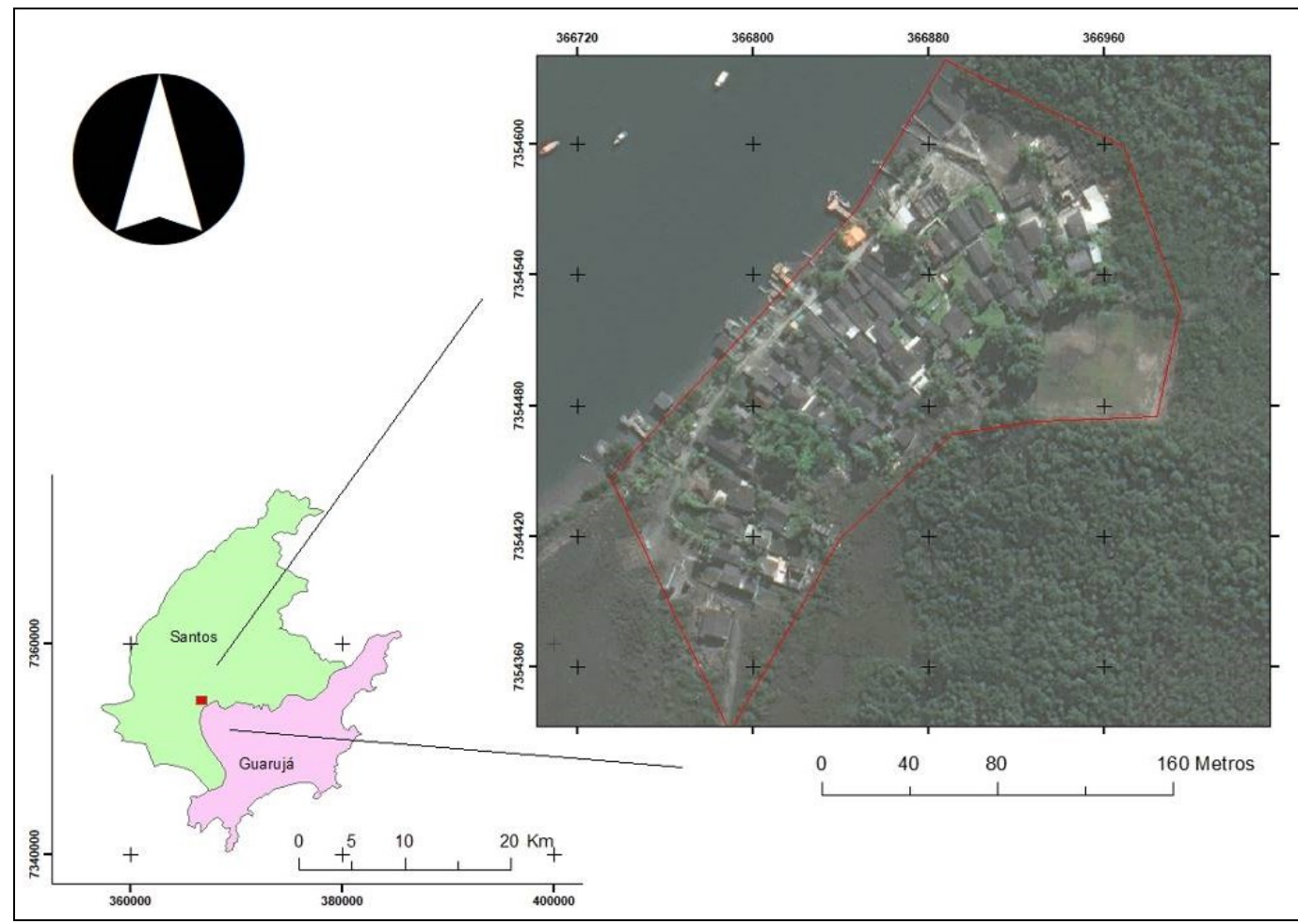

Consideradas estratégicas, as margens do estuário de Santos sempre foram alvo do interesse econômico para contínua expansão portuária tanto por parte de agentes de mercado como pelo poder público. A partir de 1970, a atividade portuária pré-existente na Baixada Santista avançou para os cais situados nos municípios do Guarujá, distrito de Vicente de Carvalho. Essa expansão para a margem oposta do canal de Santos, além de implicar em conflitos pela ocupação do espaço com as populações já estabelecidas, deu-se sobre áreas de manguezais, algumas ainda bastante intocadas e outras em estado de regeneração, chocando-se com a legislação em vigor desde 1965 e ratificada em 1988 (ROMANI, 2010). Segundo Romani (2010), uma das comunidades que sofrem o impacto direto da expansão portuária corresponde à do Ilha Diana, que se localiza próxima ao terminal de inflamáveis (depósitos de combustíveis, e produtos utilizados por indústrias de fertilizantes, siderúrgicas e petroquímicas).

Neste ínterim, intervenções humanas, além dos eventos naturais, tem se agravado pela deterioração ambiental e problemas surgem em todas as escalas. Segundo Hogan \& Marandola Jr. (2006), são "os riscos ambientais e a vulnerabilidade dos ecossistemas, ou das pessoas com relação às dinâmicas e as consequências ambientais que aprofundam e/ou promovem a vulnerabilidade social".

Freitas \& Gomes (1997, apud NASCIMENTO \& LARANJA, 2008) afirmam que: se por um lado os avanços científicos e tecnológicos contribuíram para a redução da prevalência de certas doenças associadas à fome e à pestilência, por outro, expõem milhões de pessoas todos os dias a seus locais de moradia ou trabalho, à cadeia alimentar, ao solo em que pisam, ao ar que respiram e às águas que consomem.

Considerando as questões ambientais apontadas para a comunidade em estudo, procurou-se lançar mão de técnicas de análise de risco para, neste trabalho, por meio de método inovador, identificar e relacionar fatores de risco de diversas origens que pudessem ameaçar a qualidade de vida da população local, em especial a saúde de seus integrantes. A seleção da comunidade do Ilha Diana como foco deste estudo também se deveu ao seu tamanho e área de abrangência reduzida, facilitando o levantamento de informações "in loco", as características típicas do local, as limitações técnicas e orçamentárias para o estudo e outros fatores contribuintes. 
A categoria de risco à saúde humana está relacionada às ciências da saúde. No entanto, existe uma dificuldade de tornar estes estudos voltados para a geografia da saúde, considerando que as atividades humanas estão intimamente correlacionadas aos processos de (re) produção do espaço (NASCIMENTO \& LARANJA, 2008). Ainda segundo esses autores, a relação de produção do espaço entre o ambiente e a saúde define um campo de conhecimento como "saúde ambiental" ou "saúde e ambiente". A Organização Mundial de Saúde (OMS) considera que tal relação incorpora elementos e fatores que podem tocar a saúde, considerando: exposição a fatores específicos como substâncias químicas e elementos biológicos; situações que interferem no estado psíquico do indivíduo e, também, fatores relacionados aos aspectos negativos do desenvolvimento social e econômico dos países (NASCIMENTO \& LARANJA, 2008).

Nesse sentido, ainda que a regularização fundiária buscada nos últimos anos das áreas da União tenha sido obtida pela comunidade do Ilha Diana, junto a Superintendência de Patrimônio da União (SPU) (TORRES et al., 2016) no final de 2017, ou seja, no decorrer da realização desse trabalho, ainda restam fatores que expõem a comunidade à riscos e a mantêm em uma situação de vulnerabilidade socioambiental. Um desses fatores é a contínua expansão industrial na região em que está localizada, uma vez que o modo de vida e sustento das famílias da ilha pode ser influenciado diretamente pelas mudanças nas condições ambientais locais, levando em conta a dependência do uso do território e seus arredores para a atividade pesqueira, fonte de renda mensal e também de parte de sua alimentação.

Nesse contexto, o objetivo deste artigo é propor uma abordagem multidisciplinar que possibilite indicar as possíveis ameaças para a saúde e a qualidade de vida da comunidade do llha Diana.

\section{MATERIAL E MÉTODOS}

Neste trabalho foi aplicada uma metodologia envolvendo elementos presentes na norma ABNT ISO 31000 , a qual propõe diretrizes que se aplicam a qualquer setor ou indústria para gerenciamento de riscos. Cabe citar que nesse artigo foi adotada a definição de "risco" como "a possibilidade de ocorrência de eventos indesejados". Já o termo "ameaça" aqui se refere "à presença de fatores ou condições causadoras de eventos indesejados".

Para a identificação das ameaças sociais existentes na comunidade foi considerado que o "elemento em risco" a ser analisado seria a "qualidade de vida" dos habitantes da Ilha. Essa definição foi adotada para permitir a adaptação das técnicas de análise de riscos reconhecidamente utilizadas na indústria para a questão social, objeto deste estudo. Assim, considerando a análise efetuada no trabalho, a Qualidade de Vida (QV) foi composta por dois tópicos: Social e Ambiental.

O principal método utilizado para identificação das ameaças sociais adotado para este trabalho foi a APP - Análise Preliminar de Perigos. A sigla "APP" derivou diretamente da sigla "PHA", do inglês: "Preliminary Hazard Analysis", cuja tradução, apesar de significar "perigos" (Hazard), estaria relacionada ao método de análise preliminar de "ameaças". A Análise Preliminar de Perigos (APP) é uma metodologia indutiva estruturada, desenvolvida para identificar os potenciais ameaças decorrentes da instalação de novas unidades industriais e sistemas, ou da própria operação de uma planta industrial quando da ocorrência de modificações nas operações ou implantação de novas atividades (STEPHENSON, 2000).

Apesar das ferramentas tradicionais e mais utilizadas na análise de riscos, como é o caso da APP, não obedecerem a critérios rígidos ou normas bem definidas para sua aplicação, constituindo-se na prática de uma definição da lógica envolvida no processo, alguns autores definiram modelos para sua utilização. Para este trabalho, adotou-se a aplicação de questionário (contendo 58 questões - Anexo I), especificamente adaptado a partir do questionário de censo demográfico do IBGE, visando identificar a percepção de ameaças da comunidade, além de compreender as visões, queixas, gostos, sentimentos e outras opiniões pessoais dos moradores sobre o ambiente que habitam. As informações provenientes do questionário foram divididas em 7 categorias: Saúde, Moradia, Infraestrutura, Transporte, Segurança, Econômico-financeiro, Ensino e Sensação de Pertencimento. 
Dentre os 210 moradores da ilha, foram entrevistados 19 residentes, representando 17 núcleos familiares. Algumas das perguntas, realizadas aos 19 entrevistados, expandiram-se aos seus familiares (por ex. as questões referentes ao grau de escolaridade e de doenças dos moradores da habitação). Essa totalidade de pessoas representa aproximadamente $10 \%$ dos residentes na Ilha (com base nos dados do Censo da Prefeitura de Santos do ano de 2010).

Partindo-se do pressuposto de que a qualidade de vida da população local seria o elemento em risco a ser avaliado, e que este se desdobra nos itens anteriormente mencionados, as questões foram direcionadas para a caracterização dos subitens sociais e as possíveis ameaças à sua qualidade, quantidade/disponibilidade, etc. Como exemplo, sabendo-se que a qualidade de vida de um indivíduo depende da qualidade do seu atendimento de saúde, as questões desse tema abordaram a caracterização do atendimento prestado na Ilha, o acesso dos moradores a outras formas de atendimento (consultas, pronto atendimento, emergências) e as respectivas qualidades, disponibilidades e níveis de satisfação. Ainda foram utilizadas informações complementares das pesquisas de campo na ilha (ex: informações sobre o posto de saúde e escola local) e outras disponíveis no levantamento realizado pela prefeitura de Santos, em 2010, no Termo de Autorização de Uso Sustentável (TAUS), pelo Instituto Brasileiro Geografia e Estatísticas (IBGE), pelo Departamento de Informática do SUS (DATASUS) e em outros estudos região como o de Stori (2010).

O tópico Ambiental também foi considerado para compor a Qualidade de Vida da população da comunidade. Deste modo, foram realizadas análises ambientais cujas amostras obtidas durante o período de execução do projeto (amostras de inverno e verão) foram coletadas com o intuito de abranger as principais propriedades bióticas e abióticas. A partir das análises físico-químicas da água e de metais no sedimento do rio, identificou-se a qualidade do ecossistema local e de que forma tais parâmetros podem influenciar na qualidade de vida e na saúde dos moradores, uma vez que o solo e a água da região são utilizados em atividades de lazer e para a obtenção de alguns tipos alimentos (mariscos, peixes, hortaliças). A Figura 2 indica a malha amostral utilizada nas análises ambientais (na água e no sedimento de fundo do rio) e a Figura 3 ilustra as etapas de desenvolvimento do projeto. O presente artigo discorre, principalmente, das fases 2 e 3.

Figura 2 - Mapa de distribuição das amostras, de água e de solo, coletadas ao longo do Rio Diana. Amostras coletadas no inverno, à esquerda e as coletadas no verão, à direita.
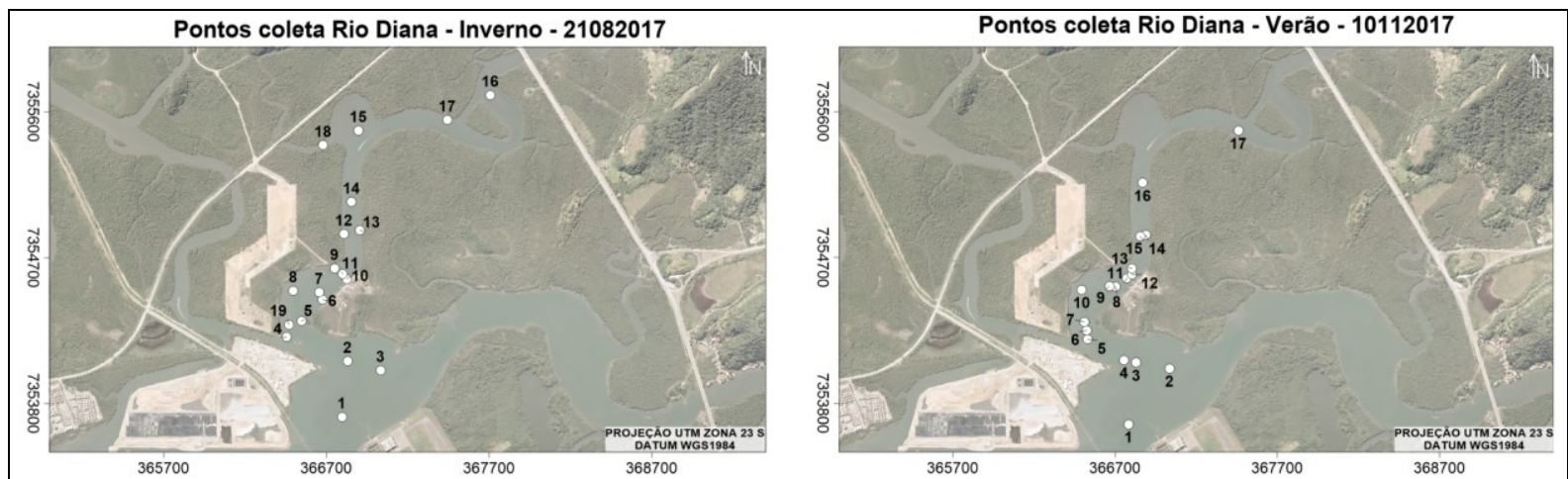
Figura 3 - Fluxograma de desenvolvimento do projeto.

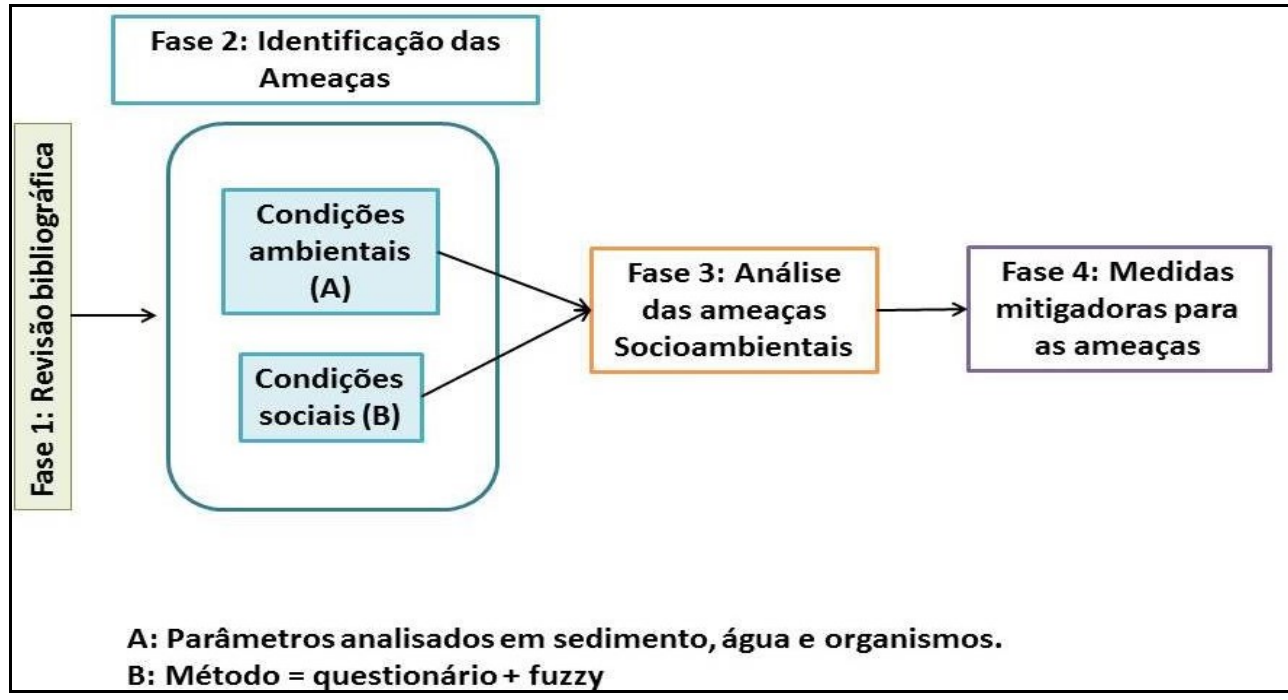

A seguir são descritas as análises ambientais que foram realizadas em amostras de água, de sedimento e em organismos colhidas ao longo do Rio Diana:

Em água: Legislação utilizada para comparar os resultados em água: Rio classe 2 - Resolução Conama 357/2005.

a) Parâmetros físico-químicos: Amônia, Nitrato, Nitrito, Fósforo Total, pH e Oxigênio Dissolvido (OD);

b) Metais: Cloro - $\mathrm{Cl}$, Manganês - Mn, Ferro - Fe, Zinco - Zn, Cromo - Cr, Cobre - $\mathrm{Cu}$, Níquel - Ni e Prata - Ag.

Em Sedimento do Rio Diana: Legislação utilizada para comparar os resultados de metais e HPAs no sedimento do Rio: Conama 454/2012 (metais e HPAS), para HPAs também foi utilizada legislação internacional NOAA (National Oceanic and Atmospheric Administration) e USEPA (United States Environmental Protection Agency).

a) Metais (Arsênio - As, Cádmio - Cd, Chumbo - Pb, Cobre - $\mathrm{Cu}$, Cromo - Cr, Mercúrio $\mathrm{Hg}$, Níquel - Ni, Zinco - Zn);

b) Compostos orgânicos (HPAs).

Para a correlação entre os aspectos sociais e ambientais com as ameaças identificadas em cada tópico analisado, buscou-se a adoção de um método inovador. Para tanto, foi estudado e utilizado o QCA - Qualitative Comparative Analysis (Análise Qualitativa Comparativa). Este tem sido utilizado nas Ciências Políticas para a análise de questões que envolvam número significativo de variáveis, com baixa quantidade de amostras sobre elas. Para sua aplicação, neste caso, há a possibilidade de uso da lógica Difusa (lógica fuzzy).

A Lógica Fuzzy, também denominada de lógica difusa ou nebulosa, foi primeiramente introduzida em 1930, pelo filósofo e lógico polonês Jan Lukasiewicz. Através do estudo de termos do tipo "alto", "velho" e "quente" (subjetivos), ele propôs a utilização de um intervalo de valores $[0,1]$ que indicaria a possibilidade que uma declaração fosse verdadeira ou falsa.

Ao contrário da Lógica convencional, a Lógica Difusa utiliza a ideia de que todas as variáveis, especialmente as subjetivas (temperatura, altura, velocidade, etc.), admitem graus de pertinências. Com isso, a Lógica Difusa tenta modelar o senso de palavras, tomada de decisão ou senso comum do ser humano. Assim, nesse método, um elemento pertence a um conjunto com certo grau de pertinência, fazendo com que uma determinada sentença possa ser parcialmente verdadeira e parcialmente falsa. Além do mais, um mesmo elemento pode ter graus de pertinências diferentes de 0 para mais de um conjunto Fuzzy (MARRO et al, 2010). 
Essas características metodológicas se adequam na abordagem de questões sociais e ambientais, especialmente por se constituírem em variáveis qualitativas e subjetivas, com relações desconhecidas entre elas. Portanto, foram aqui utilizadas, tanto na análise individual das questões ambientais e sociais, quanto na sua correlação posterior, visando identificar o impacto de cada uma delas na qualidade de vida do morador da llha, o que definiria sua tomada de decisão em permanecer ou abandonar seu modo de vida.

A aplicação desse método é ideal para casos com grande complexidade, em que as condições tendem a ser derivadas de variáveis quantitativas contínuas. Essas variáveis quantitativas são transformadas em ponderações do tipo Difusa (Fuzzy), variando no intervalo de 0 a 1 , a partir do nível de presença das condições, representando, de um lado, a exclusão completa da condição (0) e, de outro, sua completa presença (1).

Inicialmente foram definidas as variáveis que comporiam a análise dois conjuntos Difusos (Fuzzy), foi estabelecido que a Qualidade de Vida da Ilha (denominado na Figura 4 de QV Ilha) seria composta por dois tópicos: sociais (QV Social na Figura 4) e ambientais (QV Ambiental na Figura 4). A análise dos resultados dos questionários e das informações apuradas pelo levantamento da prefeitura de Santos em 2010, IBGE, DATASUS e, demais referências adotadas para o trabalho, balizou a escolha das variáveis sociais a serem abordadas. Dentre os parâmetros escolhidos para compor o QV Social, aqueles abordados nesse artigo são os subtópicos de Saúde e de Infraestrutura. O QV Ambiental foi definido com base no resulta do das análises ambientais realizadas. Como exemplo da aplicação da lógica Difusa temos o sub-tópico Saúde, o qual considera: 1) "Qualidade do Atendimento do Posto de Saúde na Ilha", definida com base no percentual de respostas do tipo "bom" do questionário aplicado; 2) "Morbidade Relativa Ilha-Santos", definida com base no cálculo da taxa de incidência de doenças nos moradores da Ilha dividida sobre a taxa de incidência de doenças na população de Santos (dados do DATASUS); e 3) "Mortalidade Relativa Ilha-Santos", definida com base no cálculo da taxa de mortalidade nos moradores da llha dividida sobre a taxa de mortalidade na população de Santos (dados do DATASUS). A Figura 4 ilustra o processo metodológico de composição das variáveis ambientais e sociais, na lógica Difusa (Fuzzy).

Figura 4 - Definição da relação entre as variáveis no modelo Fuzzy. Adaptado de Blanco et al (2019).






\section{RESULTADOS E DISCUSSÃo}

\section{Considerações a partir da aplicação do questionário, dos dados provenientes do DATASUS e das análises ambientais}

Os resultados obtidos a partir da aplicação do questionário refletiram a percepção de risco dos entrevistados, uma vez que lançam mão de seus conhecimentos e experiências próprias (subjetividade) para a análise das ameaças a que se expõem, de forma intuitiva. Entretanto, estas considerações não são desprezíveis e, apesar de não embasadas em conhecimentos científicos, podem estar referenciadas em ameaças reais, a serem consideradas pela análise a que se pretende neste trabalho. Basta que as ameaças identificadas sejam analisadas, visando diminuir a subjetividade inerente ao processo, bem como sua supra ou sub ponderação. Há ainda, que se considerarem, as ameaças não percebidas pela população, mas que estão presentes no cotidiano da comunidade. O método APP considerou estas questões.

\section{Saúde}

Embora quase todos os entrevistados tenham se declarado usuários do posto de saúde presente na Ilha (17 dos 19 entrevistados), as queixas estão associadas principalmente a limitação do horário de atendimento do posto, a oferta de baixa variedade de medicamentos e a prestação de serviços médicos apenas para casos de pouca complexidade. Reconhece-se, que esses pontos interferem no cotidiano da comunidade, entretanto, os serviços prestados estão em conformidade às atribuições correspondentes a unidade de saúde do local. Alternativas para os apontamentos listados devem averiguar de forma mais profunda se o serviço de saúde está deixando de seguir princípios fundamentais do SUS como o da equidade, universalidade e descentralização. Outras soluções estão relacionadas ao princípio do controle social, o qual garante que a população deve participar do processo de decisão do funcionamento de saúde como, por exemplo, por meio dos conselhos locais e municipais de saúde e das conferências de saúde.

Ainda com relação à saúde, para casos de emergência, disponibiliza-se um barco para transporte até o continente que pode ser solicitado por telefone. Entretanto, nenhum dos entrevistados mencionou isso ao responder o questionário, o que demonstra o desconhecimento deste serviço. Transportes de emergência também são realizados por barcos dos próprios moradores, os quais se oferecem em transportar aqueles que precisam de atendimento de emergência fora da ilha. Nesse tópico, nota-se que há uma percepção errônea (superestimada), por parte da população, da inexistência de atendimento a estas situações. Essa ameaça pode ser tornar real, pois a falta de conhecimento do serviço ofertado para estes casos pode acarretar atraso no atendimento emergencial.

No levantamento de internações realizado no banco de dados DATASUS (entre 1998 e 2016) foram encontrados 45 registros de internações (28 mulheres e 17 homens). Os motivos das internações estavam identificados pelo "CID10", sendo que corresponderam, majoritariamente, aos problemas no aparelho digestivo, respiratório e pneumonia, complicações de pós-parto e abortos. Apenas uma morte a partir da internação foi registrada ao longo desses anos. As respostas ainda indicaram que casos de hipertensão são comuns na ilha. Esses casos documentados pela pesquisa, especialmente os que dizem respeito às doenças respiratórias, possuem relação com os índices estimados para a população brasileira e com os índices da região metropolitana de São Paulo, relatados por Stori (2010) para doenças respiratórias e sanguíneas, como leucopenias e anemias nas regiões de Santos, Cubatão, São Vicente, Bertioga e Vicente de Carvalho.

Por fim, o posto oferta consultas e pronto atendimento. Com relação aos horários, existe de fato a limitação institucional dos postos de saúde. Por este motivo, e pela limitação do escopo de atendimento, muitas necessidades de saúde da comunidade são atendidas fora da ilha. Entretanto, entende-se que o posto corresponde a uma unidade básica, dimensionada de forma compatível com a população que atende, não sendo esperado que este contemple demandas de maior complexidade, não representando uma ameaça à qualidade de vida da população. Como avaliação geral do atendimento médico na ilha, foi obtido que 13 pessoas o consideram como bom, 3 como médio, 2 ruim e 1 não respondeu. 


\section{Infraestrutura}

Os resíduos sólidos são acumulados em uma porção de terreno na ilha, sendo na comunidade recolhido três vezes por semana e levado para Santos uma vez na semana, seguindo então para sua destinação final. Os entrevistados afirmaram gerar em suas residências em média 60 litros (1 sacola plástica comum) de resíduos por dia. Como os resíduos são retirados regularmente, não havendo acúmulo significativo no chão da comunidade e, portanto, não existindo exposição das pessoas ao resíduo "a céu aberto", esse tópico não foi considerado como uma ameaça à saúde da população.

Sobre a destinação do efluente doméstico (esgoto), 14 pessoas afirmam que o lançamento se dá ou no mangue ou no Rio Diana. A avaliação geral dos serviços de saneamento da ilha pelos entrevistados foi: 12 pessoas consideraram "bom", 5 "médio" e 2, "ruim". No que se refere ao serviço de coleta e tratamento de esgoto doméstico das residências da llha, é interessante notar que as respostas dos moradores ao questionário não apontaram a inexistência deste tipo de serviço como uma ameaça socioambiental. A provável justificativa para tal reside no fato da percepção de risco desta população estar subestimada para esta questão.

As visitas de campo comprovaram a inexistência do serviço de saneamento (Figura 5), considerandoo como uma ameaça não só à saúde dos próprios moradores (ex: proliferação de doenças), como possível fator de impactos ambientais no solo, na biota e no Rio Diana. A figura 5 mostra um mosaico de fotos ilustrando o despejo de efluente doméstico em diferentes localidades da comunidade. A questão da inexistência de um sistema público de coleta e tratamento do esgoto foi considerada como uma ameaça social e ambiental.

Figura 5 - Mosaico de fotos ilustrando o efluente doméstico sendo despejado em diferentes pontos da comunidade



No mapa localizado no canto superior direito há a indicação do local do despejo por meio dos círculos nas cores: preta, verde, roxa, amarela e azul. Os círculos das cores citadas fazem correspondência com as fotos do mosaico que possuem círculos e setas de mesmas cores. Observa-se que os círculos vermelhos são apenas representativos e indicam outras localidades de despejo de efluente doméstico que não foram ilustrados com fotos. 


\section{Análises Ambientais e sua relação com a categoria "Saúde"}

Os resultados das análises ambientais mostraram que parte dos parâmetros analisados na água e no sedimento do Rio está, em alguns pontos, acima do estabelecido por legislações ambientais vigentes e padrões internacionais. A tabela 1 indica quais parâmetros foram identificados com valores acima do estabelecido nas legislações comparadas no trabalho. As tabelas de $\mathbf{2}$ a $\mathbf{4}$ indicam os resultados das análises ambientais, nelas estão indicadas as amostras que ficaram acima de valores estabelecidos pelas legislações vigentes, utilizadas nas comparações realizadas no estudo. Alguns dos parâmetros analisados, como os físico-químicos da água, indicam presença de esgoto doméstico. Os resultados encontrados nas análises ambientais realizadas representam a complexidade de sistemas estuarinos, e mostraram que este ambiente não é influenciado por "barreiras administrativas". A qualidade ambiental encontrada nos compartimentos estudados reflete as condições sanitárias de uma macrorregião, sendo possivelmente influenciada por outros fatores, como os efluentes gerados pelos terminais portuários e pelo polo industrial de Cubatão.

Outros parâmetros analisados que merecem destaque são os resultados para as análises de metais e compostos orgânicos (HPAs). A análise de compostos orgânicos em amostras sedimentares indicou que o material analisado não apresenta valores acima do estabelecido pela resolução Conama 454/2012, tanto na análise individual dos compostos quanto na soma total destes. De acordo com a IARC (International Agency for Research on Cancer), os compostos que apresentam algum potencial carcinogênico são os benzo[a]antraceno, benzo[b]fluoranteno, benzo[a]pireno, indeno[1,2,3c,d]pireno, dibenzo[a,h]antraceno (QUEIROZ, 2011). Nas amostras sedimentares do Rio Diana (Tabela 4), o composto dibenzo[a,h]antraceno foi encontrado com limiar acima do estabelecido pelas convenções internacionais (NOAA/USEPA). Utilizando os valores estabelecidos pela NOAA/USEPA, a soma total de HPAs está abaixo do estabelecido.

Os índices de HPAs, anteriormente mencionados, podem ser atribuídos à combustão dos combustíveis fósseis utilizados em barcos de diversos portes (lazer, navios, transporte de pessoas), ao aporte de dejetos das indústrias, portos, marinas, e das atividades de navegação nas proximidades da região, visto que a Baixada Santista comporta o núcleo industrial mais importante do Brasil e o maior porto em volume de carga, de forma que este contaminante pode ter sido disponibilizado para o rio, pela oscilação da maré.

A Tabela 5 sumariza os metais encontrados acima do estabelecido pela legislação ambiental brasileira, juntamente com as prováveis fontes e possíveis efeitos à saúde humana decorridos da exposição a estes. Com o auxílio dessa tabela, no que se refere à análise de metais, infere-se que os metais citados poderiam representar alguma ameaça para a população da llha, pois algumas amostras de água e de sedimento do rio estão acima do estabelecido por legislações. Entretanto, a via de exposição dos moradores não foi confirmada, o que dificulta a análise da ameaça a que a população está exposta.

Tabela 1 - Síntese dos parâmetros identificados como acima do estabelecido na legislação comparada.




Tabela 2 - Resultados obtidos a partir da análise de parâmetros físico-químicos e inorgânicos obtidos em amostras superficiais de água do Rio para os períodos de inverno e de verão. Para a comparação dos valores foi utilizada a Resolução CONAMA 357/2005. < L indica que os valores foram menores do que o estabelecido pela legislação citada.

\begin{tabular}{c|cc|ccccc}
\hline \multirow{2}{*}{ Estação } & \multicolumn{2}{|c|}{ Inverno } & \multicolumn{5}{c}{ Verão } \\
\hline Ponto de Amostragem & Fósforo $(\mathrm{mg} / \mathrm{L})$ & $\mathrm{OD}(\mathrm{mg} / \mathrm{L})$ & Amônia & Nitrato & Nitrito & Fósforo & $\mathrm{OD}$ \\
\hline 1 & 0,245 & $<\mathrm{L}$ & $<\mathrm{L}$ & $<\mathrm{L}$ & $<\mathrm{L}$ & $<\mathrm{L}$ & $<\mathrm{L}$ \\
\hline 2 & 0,245 & $<\mathrm{L}$ & $<\mathrm{L}$ & $<\mathrm{L}$ & $<\mathrm{L}$ & $<\mathrm{L}$ & $<\mathrm{L}$ \\
3 & 0,245 & $<\mathrm{L}$ & $<\mathrm{L}$ & $<\mathrm{L}$ & $<\mathrm{L}$ & $<\mathrm{L}$ & 3,83 \\
4 & 0,245 & $<\mathrm{L}$ & $<\mathrm{L}$ & $<\mathrm{L}$ & $<\mathrm{L}$ & $<\mathrm{L}$ & $<\mathrm{L}$ \\
5 & 0,245 & $<\mathrm{L}$ & $<\mathrm{L}$ & $<\mathrm{L}$ & $<\mathrm{L}$ & $<\mathrm{L}$ & 3,42 \\
6 & 0,245 & 3,6 & $<\mathrm{L}$ & $<\mathrm{L}$ & $<\mathrm{L}$ & $<\mathrm{L}$ & 3,38 \\
7 & 0,245 & $<\mathrm{L}$ & 1,21 & 2,5 & & 0,75 & $<\mathrm{L}$ \\
8 & 0,245 & 3,9 & 1,21 & $<\mathrm{L}$ & 0,5 & 1 & $<\mathrm{L}$ \\
9 & 0,245 & $<\mathrm{L}$ & $<\mathrm{L}$ & $<\mathrm{L}$ & $<\mathrm{L}$ & $<\mathrm{L}$ & 3,74 \\
10 & 0,245 & 4 & 1,21 & 2,5 & 0,5 & 1 & 3,6 \\
11 & 0,245 & $<\mathrm{L}$ & $<\mathrm{L}$ & $<\mathrm{L}$ & $<\mathrm{L}$ & $<\mathrm{L}$ & 3,24 \\
12 & 0,245 & $<\mathrm{L}$ & $<\mathrm{L}$ & $<\mathrm{L}$ & $<\mathrm{L}$ & $<\mathrm{L}$ & 3,03 \\
13 & 0,245 & $<\mathrm{L}$ & $<\mathrm{L}$ & $<\mathrm{L}$ & $<\mathrm{L}$ & $<\mathrm{L}$ & 3,5 \\
14 & 0,245 & 4 & 1,21 & 2,5 & $<\mathrm{L}$ & 0,75 & $<\mathrm{L}$ \\
15 & 0,245 & $<\mathrm{L}$ & $<\mathrm{L}$ & $<\mathrm{L}$ & $<\mathrm{L}$ & $<\mathrm{L}$ & $<\mathrm{L}$ \\
16 & 0,245 & $<\mathrm{L}$ & $<\mathrm{L}$ & $<\mathrm{L}$ & $<\mathrm{L}$ & $<\mathrm{L}$ & $<\mathrm{L}$ \\
17 & 0,245 & $<\mathrm{L}$ & 1,21 & $<\mathrm{L}$ & $<\mathrm{L}$ & 1 & $<\mathrm{L}$ \\
\hline & 0,245 & $<\mathrm{L}$ & $<\mathrm{L}$ & $<\mathrm{L}$ & $<\mathrm{L}$ & $<\mathrm{L}$ & $<\mathrm{L}$ \\
\hline & & & & & & &
\end{tabular}


Tabela 3 - Resultados obtidos nas análises de metais em amostras superficiais de água para os períodos de inverno e de verão. Para a comparação dos valores foi utilizada a Resolução CONAMA 357/2005. < L indica que os valores foram menores do que o estabelecido pela legislação citada.

\begin{tabular}{|c|c|c|c|c|c|c|c|c|}
\hline Estação & \multicolumn{4}{|c|}{ Inverno } & \multicolumn{4}{|c|}{ Verão } \\
\hline Ponto de Amostragem & Cloro $(\mu \mathrm{g} / \mathrm{l})$ & Manganes (mg/l) & Ferro $(\mathrm{mg} / \mathrm{L})$ & Zinco $(\mathrm{mg} / \mathrm{L})$ & Cloro $(\mu \mathrm{g} / \mathrm{l})$ & Manganes $(\mathrm{mg} / \mathrm{l})$ & Ferro (mg/L) & Zinco (mg/L) \\
\hline 1 & 2058674,21 & $<\mathrm{L}$ & 2,41 & $<\mathrm{L}$ & $<\mathrm{L}$ & $<\mathrm{L}$ & $<\mathrm{L}$ & $<\mathrm{L}$ \\
\hline 2 & 1468480,34 & 0,17 & 4,09 & 0,18 & $<\mathrm{L}$ & $<\mathrm{L}$ & $<\mathrm{L}$ & $<\mathrm{L}$ \\
\hline 3 & 2552849,90 & 0,13 & 1,99 & $<\mathrm{L}$ & $<\mathrm{L}$ & $<\mathrm{L}$ & $<\mathrm{L}$ & $<\mathrm{L}$ \\
\hline 4 & 3909189,75 & 0,16 & 2,48 & $<\mathrm{L}$ & $<\mathrm{L}$ & $<\mathrm{L}$ & $<\mathrm{L}$ & $<\mathrm{L}$ \\
\hline 5 & 1843868,35 & 0,21 & 3,75 & 0,22 & $<\mathrm{L}$ & $<\mathrm{L}$ & $<\mathrm{L}$ & $<\mathrm{L}$ \\
\hline 6 & 2328157,41 & $<\mathrm{L}$ & 1,79 & $<\mathrm{L}$ & $<\mathrm{L}$ & $<\mathrm{L}$ & $<\mathrm{L}$ & $<\mathrm{L}$ \\
\hline 7 & 4830504,66 & 0,35 & 1,43 & 0,12 & 1584000,00 & $<\mathrm{L}$ & 1,17 & $<\mathrm{L}$ \\
\hline 8 & 3924854,98 & 0,18 & 2,76 & $<\mathrm{L}$ & 1614000,00 & $<\mathrm{L}$ & 1,81 & $<\mathrm{L}$ \\
\hline 9 & 3022611,60 & $<\mathrm{L}$ & 0,60 & $<\mathrm{L}$ & $<\mathrm{L}$ & $<\mathrm{L}$ & $<\mathrm{L}$ & $<\mathrm{L}$ \\
\hline 10 & 2643380,09 & $<\mathrm{L}$ & 2,93 & 0,23 & 1401000,00 & 0,10 & 1,19 & $<\mathrm{L}$ \\
\hline 11 & 3884865,72 & $<L$ & 2,36 & 0,22 & $<\mathrm{L}$ & $<\mathrm{L}$ & $<L$ & $<L$ \\
\hline 12 & 4846813,05 & $<\mathrm{L}$ & 1,88 & 0,19 & $<\mathrm{L}$ & $<\mathrm{L}$ & $<\mathrm{L}$ & $<\mathrm{L}$ \\
\hline 13 & 2247313,81 & $<\mathrm{L}$ & 2,26 & $<\mathrm{L}$ & $<\mathrm{L}$ & $<L$ & $<\mathrm{L}$ & $<L$ \\
\hline 14 & 3668830,65 & $<\mathrm{L}$ & 2,94 & $<\mathrm{L}$ & 1024000,00 & 0,42 & 3,56 & 0,21 \\
\hline 15 & 1455157,84 & 4,57 & $<L$ & $<L$ & $<L$ & $<\mathrm{L}$ & $<L$ & $<L$ \\
\hline 16 & 3115669,84 & $<L$ & $<L$ & $<\mathrm{L}$ & $<\mathrm{L}$ & $<\mathrm{L}$ & $<\mathrm{L}$ & $<\mathrm{L}$ \\
\hline 17 & 2422399,95 & $<L$ & $<\mathrm{L}$ & $<\mathrm{L}$ & 1392000,00 & $<L$ & 2,25 & $<L$ \\
\hline 18 & 3738127,43 & $<\mathrm{L}$ & $<\mathrm{L}$ & $<\mathrm{L}$ & $<\mathrm{L}$ & $<\mathrm{L}$ & $<\mathrm{L}$ & $<\mathrm{L}$ \\
\hline
\end{tabular}


Tabela 4 - Concentração dos 16 HPAs considerados mais perigosos pela IARC nas amostras de sedimento do Rio Diana e sua soma total. Em vermelho aqueles considerados como tendo algum potencial carcinogênico, grifados em azul aqueles que apresentaram valores acima do estabelecido pela IARC.

\begin{tabular}{|c|c|c|c|c|c|c|c|c|c|c|c|c|c|c|c|c|}
\hline EST. & $\begin{array}{l}\text { nafta- } \\
\text { leno }\end{array}$ & $\begin{array}{c}\text { acenafti } \\
\text {-leno }\end{array}$ & $\begin{array}{c}\text { acenaf- } \\
\text { teno }\end{array}$ & $\begin{array}{l}\text { fluo- } \\
\text { reno }\end{array}$ & $\begin{array}{l}\text { fenan- } \\
\text { treno }\end{array}$ & $\begin{array}{l}\text { antra- } \\
\text { ceno }\end{array}$ & $\begin{array}{c}\text { fluoran } \\
\text {-teno }\end{array}$ & pireno & $\begin{array}{l}\text { benzo[a] } \\
\text { antraceno }\end{array}$ & criseno & $\begin{array}{c}\text { benzo[b } \\
\text { +k]fluor } \\
\text { anteno }\end{array}$ & $\begin{array}{l}\text { benzo[a] } \\
\text { pireno }\end{array}$ & $\begin{array}{c}\text { dibenzo[a,h] } \\
\text { antraceno }\end{array}$ & $\begin{array}{c}\text { indeno }[1,2 \\
3- \\
\text { c,d]pireno }\end{array}$ & $\begin{array}{c}\text { benzo[g,h,i] } \\
\text { perileno }\end{array}$ & $\sum_{\text {HPAS }}^{\sum_{16}}$ \\
\hline 1 & $<1,60$ & $<3,70$ & $<1,30$ & $<1,30$ & 5,45 & $<1,10$ & 1,74 & 1,75 & $<1,20$ & $<1,20$ & 21,14 & 11,18 & 2,58 & 10,82 & 10,43 & 65,09 \\
\hline 2 & 5,4 & $<3,70$ & 1,8 & 2,35 & 19,15 & 6,63 & 77,83 & 70,19 & 13,61 & 11,89 & 133,93 & 69,15 & 13,45 & 60,5 & 57,9 & 543,81 \\
\hline 3 & 5,1 & $<3,70$ & 1,55 & 2,05 & 5,94 & 11,38 & 27,52 & 26,04 & 5,24 & 7,91 & 52,26 & 26,08 & 5,14 & 22,96 & 22,54 & 221,73 \\
\hline 4 & 3,2 & $<3,70$ & 1,35 & 1,89 & 5,7 & 2,32 & 19,46 & 19,38 & 3,42 & 3,17 & 38,55 & 19,04 & 4,27 & 18,82 & 18,57 & 159,17 \\
\hline 5 & 8,3 & $<3,70$ & 2,7 & 3,34 & 12,65 & 5,79 & 52,34 & 49,41 & 8,81 & 7,93 & 98,22 & 49,58 & 11,76 & 46,15 & 47,1 & 404,1 \\
\hline 6 & $<1,60$ & $<3,70$ & $<1,30$ & $<1,30$ & $<2,60$ & $<1,10$ & 3,14 & 3,59 & $<1,20$ & $<1,20$ & 7,56 & 3,48 & 1,05 & 4,39 & 4,31 & 27,52 \\
\hline 7 & 3,6 & $<3,70$ & $<1,30$ & 1,56 & 5,15 & 2,05 & 15,84 & 16,2 & 2,68 & 2,51 & 34,1 & 15,82 & 4,02 & 19,3 & 18,78 & 141,56 \\
\hline 8 & 8,5 & $<3,70$ & 3,43 & 3,5 & 13,26 & 5,99 & 24,74 & 25,31 & 5,94 & 5,48 & 72,49 & 32,02 & 9,01 & 37,37 & 35,41 & 282,42 \\
\hline 9 & 5,65 & $<3,70$ & 2,27 & 2,38 & 9,8 & 3,61 & 26,49 & 23,52 & 4,07 & 3,39 & 50,86 & 20,64 & 5,82 & 22,71 & 23,04 & 204,25 \\
\hline 10 & 4,2 & $<3,70$ & 1,71 & 2,03 & 9,76 & 3,24 & 23,08 & 24,08 & 4,09 & 3,58 & 74,18 & 31,62 & 8,49 & 39,74 & 36,4 & 266,2 \\
\hline 11 & 7,7 & $<3,70$ & 2,96 & 4,21 & 9,26 & 3,03 & 19,68 & 21,35 & 2,83 & 3,18 & 45,68 & 19,42 & - & 23,59 & 24,69 & 187,58 \\
\hline 12 & 5,32 & $<3,70$ & 2,23 & 2,46 & 6,78 & 2,78 & 14,57 & 14,32 & 2,15 & 1,94 & 28,51 & 11,55 & 3,43 & 14,56 & 14,37 & 124,97 \\
\hline 13 & 1,6 & $<3,70$ & $<1,30$ & $<1,30$ & $<2,60$ & $<1,10$ & 3,44 & 4,46 & $<1,20$ & $<1,20$ & 7,35 & 2,43 & $<1,00$ & 3,97 & 3,6 & 26,85 \\
\hline 14 & 2,17 & $<3,70$ & $<1,30$ & 1,52 & 3,03 & 1,42 & 5,81 & 6,1 & $<1,20$ & $<1,20$ & 14,14 & 4,88 & 1,58 & 8,25 & 7,5 & 56,4 \\
\hline 15 & 4,55 & $<3,70$ & 1,6 & 2,66 & 6,02 & 2,2 & 12,17 & 16,49 & 2,39 & 4,43 & 39,48 & 17,15 & 4,63 & 18,19 & 17,75 & 149,71 \\
\hline 16 & 5,51 & $<3,70$ & 1,75 & 2,77 & 11 & 2,74 & 26,05 & 24,18 & 3,41 & 3,19 & 41,38 & 18,3 & 4,72 & 18,91 & 19,2 & 183,11 \\
\hline 17 & 9,82 & $<3,70$ & 4,76 & 4,77 & 14,47 & 5,04 & 45 & 48,77 & 5,96 & 6,11 & 71,83 & 28,98 & 8,12 & 33,91 & 36,32 & 323,86 \\
\hline 18 & 4,21 & $<3,70$ & 8,36 & 5,73 & 57,68 & 9,65 & 106,55 & 71,64 & 18,02 & 16,54 & 91,46 & 39,2 & 10,68 & 32,98 & 27,09 & 499,79 \\
\hline 19 & 5,45 & $<3,70$ & 3,12 & 2,04 & 7,27 & 4,36 & 62,22 & 55,18 & 9,57 & 8,14 & 53,75 & 26,15 & 4,34 & 22 & 20,85 & 284,44 \\
\hline 20 & 1,87 & $<3,70$ & $<1,30$ & $<1,30$ & $<2,60$ & $<1,10$ & 3,21 & 3,9 & $<1,20$ & $<1,20$ & 4,06 & 1,71 & $<1,00$ & 2,04 & 2,1 & 18,89 \\
\hline
\end{tabular}


Tabela 5 - Metais encontrados acima do estabelecido por legislações nas análises realizadas na água e no sedimento do Rio Diana. A tabela também contempla as principais fontes dos metais e os possíveis efeitos à saúde humana. Fontes: Martin \& Griswold (2009); EPA (2000); ATSDR (2005).

\begin{tabular}{|c|c|c|c|c|}
\hline Metal & Amostra & Fontes & $\begin{array}{l}\text { Forma de } \\
\text { exposição }\end{array}$ & Efeitos à saúde humana \\
\hline Chumbo & $\begin{array}{l}1 \text { amostra } \\
\text { sedimento }\end{array}$ & $\begin{array}{l}\text { Fontes antrópicas: queima de } \\
\text { combustíveis fósseis, mineração e } \\
\text { manufaturas (tintas, canos antigos, } \\
\text { certos cosméticos, etc). } \\
\text { Fontes naturais: ar, solo e água }\end{array}$ & Ingestão & $\begin{array}{l}\text { http://www.scielo.br/pdf/rpsp/v15n2/20821.pdf } \\
\text { Podem afetar ossos, rins e fígado, sistemas nervoso e cardiovascular e, também existe a } \\
\text { possibilidade de serem carcinogênicos. Os estudos científicos sobre a toxicologia do } \\
\text { chumbo são desenvolvidos há mais de um século. Contudo, ainda são insuficientes as } \\
\text { informações sobre os mecanismos de ação que originam os efeitos tóxicos desse metal. Os } \\
\text { resultados da exposição ao chumbo sobre os ossos, os sistemas nervoso central e } \\
\text { cardiovascular, os rins e o fígado devem ser estudados com maior profundidade, bem como } \\
\text { os efeitos sobre a reprodução masculina e feminina, o sistema endócrino e a formação do } \\
\text { feto. Também é essencial esclarecer se o chumbo tem efeitos teratogênicos e carcinogênicos } \\
\text { em seres humanos. }\end{array}$ \\
\hline Ferro & $\begin{array}{l}\text { Amostras } \\
\text { de água }\end{array}$ & $\begin{array}{l}\text { Ampla distribuição em solo, } \\
\text { animais e plantas }\end{array}$ & Ingestão & $\begin{array}{l}\text { O ferro não apresenta efeitos graves à saúde humana, mas afeta a qualidade da água potável } \\
\text { (como exemplo alterações na cor e no odor. }\end{array}$ \\
\hline Manganês & $\begin{array}{l}\text { Amostras } \\
\text { de água }\end{array}$ & $\begin{array}{l}\text { Fontes naturais: solo, água, ar e } \\
\text { plantas; } \\
\text { Fontes antrópicas: mineração do } \\
\text { manganês para produzir a liga de } \\
\text { ferro-manganês, que é utilizada na } \\
\text { produção do aço; dióxido de } \\
\text { manganês é usado na produção de } \\
\text { fósforos, baterias secas, fogos de } \\
\text { artifícios, fertilizantes e fungicidas. }\end{array}$ & $\begin{array}{l}\text { Inalação e } \\
\text { Ingestão }\end{array}$ & $\begin{array}{l}\text { https://www.unifesp.br/reitoria/dci/publicacoes/entreteses/item/2217-manganes-um-risco- } \\
\text { invisivel } \\
\text { A ingestão crônica de quantidade diária superior a } 3 \mathrm{mg} \text {, porção adquirida pela ingestão de } \\
\text { alimentos como oleoginosas (vegetais que possuem óleos e gorduras - amendoim, } \\
\text { castanhas, amêndoas, milho, girassol, etc), comumente leva a um quadro de intoxicação } \\
\text { conhecido por manganismo. Sabe-se hoje que o distúrbio provoca permanentemente } \\
\text { tremores, dificuldades de coordenação motora e problemas de memória. }\end{array}$ \\
\hline Zinco & $\begin{array}{l}\text { Amostras } \\
\text { de água }\end{array}$ & $\begin{array}{l}\text { Fontes naturais: solo, água, ar e } \\
\text { diversos alimentos; } \\
\text { Fontes antrópicas: no revestimento } \\
\text { de aço e ferro para evitar a } \\
\text { ferrugem e corrosão (processo } \\
\text { chamado de galvanização), } \\
\text { utilizado na formação de ligas } \\
\text { como latão e bronze, na fabricação } \\
\text { de baterias secas, tintas brancas, } \\
\text { cerâmicas, borracha. }\end{array}$ & $\begin{array}{l}\text { Inalação e } \\
\text { Ingestão }\end{array}$ & $\begin{array}{l}\text { http://www.fugesp.org.br/nutricao_e_saude_conteudo.asp?id_publicacao=3\&edicao_numer } \\
\text { o=6\&menu_ordem=2 } \\
\text { A toxicidade pelo zinco é rara, geralmente quando ingerido acima de } 100 \text { a } 300 \mathrm{mg} / \text { dia. } \\
\text { Nesta eventualidade poderá causar alterações na absorção do cobre, além de provocar } \\
\text { distúrbios gastrointestinais como náuseas, vômitos, gosto metálico e dores abdominais. Uma } \\
\text { forma comum de toxicidade pelo zinco é o que ocorre nas hemodiálises, decorrente da } \\
\text { liberação do zinco contido nos adesivos plásticos usados nas bobinas de diálise, do zinco } \\
\text { existente nos tubos galvanizados destas mesmas máquinas. Nestas intercorrências crônicas, } \\
\text { os pacientes apresentam anemia, febre e distúrbios do sistema nervoso central. }\end{array}$ \\
\hline
\end{tabular}




\section{Considerações a partir da aplicação da lógica Difusa (Fuzzy): Estudo de caso do sub-tópico "Saúde"}

Para compor a categoria "Saúde", que faz parte do tópico "Qualidade de Vida Social" (QV Social, indicado na Figura 4) foram consideradas três variáveis: "Qualidade do Atendimento na llha", definida com base no percentual de respostas do tipo "bom" do questionário aplicado; "Morbidade Relativa Ilha-Santos", definida com base no cálculo da taxa de incidência de doenças nos moradores da llha dividida pela taxa de incidência de doenças na população de Santos (banco de dados DATASUS); e "Mortalidade Relativa Ilha-Santos", definida com base no cálculo da taxa de mortalidade nos moradores da llha dividida pela taxa de mortalidade na população de Santos (banco de dados DATASUS). Os técnicos analistas de riscos definiram conjuntamente com o analista de sistemas, os gráficos de pertinência das variáveis consideradas, bem como os gráficos de saída na lógica difusa, conforme indicado na Figura 6. Foi utilizado o programa "jFuzzyLogic" (JFUZZYLOGIC, 2017), de licença livre para a definição das variáveis no modelo Fuzzy.

Figura 6 - Definição dos gráficos das funções de pertinência das variáveis de entrada e de saída (QV Saúde) no modelo Fuzzy, no software "jFuzzyLogic"


Conforme indicado na Figura $\mathbf{6 d}$, a relação entre as variáveis analisadas (Mortalidade, Atendimento e Morbidade) foi definida por valores adimensionais entre 0 e 1 que caracterizam, de forma qualitativa, a pertinência aos grupos "bom" (extremidade em 1) ou "ruim" (extremidade em 0) que a variável Qualidade de Vida atribuída ao Tópico Saúde, QV_Saude, poderia assumir.

A Figura 6d, definida como o tópico Saúde - QV_Saude, é composta pelas variáveis mortalidade (Figura 6a), morbidade (Figura 6b) e qualidade do atendimento na llha (Figura 6c). As variáveis mortalidade e morbidade possuem relação inversamente proporcional com o tópico QV_Saúde enquanto a variável qualidade do atendimento na ilha assume relação diretamente proporcional.

No programa, às variáveis dos gráficos $\mathbf{6 a}$ e $\mathbf{6 b}$ foram atribuídas funções de pertinência iguais, de forma que valores $<0,7$ indicam baixa mortalidade (6a) e morbidade (6b) e, por consequência, contribuem para o aumento do valor de QV_Saude (indicado no gráfico $6 \mathbf{d}$, calculado pelo programa), deslocando para o lado "bom" desse gráfico. Para valores $>1,3$ nos gráficos de mortalidade e morbidade, a pertinência ao grupo "maior" deslocará os valores de QV_Saude para o grupo "ruim", indicando piora na avaliação do tópico Saúde. 
Para a variável "qualiAtendimentollha", indicada no gráfico $6 c$, para valores $>0,4$, a pertinência se desloca ao grupo "inadequado", o que leva a valores menores do QV_Saude, deslocando-o para o grupo "ruim". Já para valores $>0,8$, a pertinência da variável "qualiĀtendimentollha" passa a ser deslocada para o grupo "adequado", o que contribuirá para que o QV_Saude (gráfico 6d) assuma valores maiores, aproximando-se do grupo "bom".

Posteriormente, foram simulados testes de aderência do modelo proposto. As simulações destes valores geraram os gráficos das Figuras 7 a 9. Para estas simulações foram calculados os valores assumidos pelo "QV_Saude" para variações de "0,1" nas demais variáveis (Mortalidade, Atendimento e Morbidade), combinadas duas a duas e fixando-se a terceira.

O resultado final obtido no tópico QV_Saude indicou um valor de 0,69 para os valores de entrada (mortalidade, morbidade e qualidade no atendimento), o qual significa que a qualidade de vida decorrente destas variáveis tem perto de $60 \%$ de pertinência ao "conjunto" de resultado "bom" e perto de $40 \%$ de pertinência ao "conjunto" de resultado "ruim" (Figura 6d). Isto é, trata-se de um resultado mediano, tendendo a bom, quando consideradas as condições de qualidade do atendimento e tipos de serviços na llha.

Figura 7 - Gráfico dos testes de aderência do modelo para os valores assumidos por "QV Saúde", variando-se os valores de "Mortalidade" e "Morbidade", com a variável "Qualidade Atendimento" fixa em 0,7 , calculados no programa "jFuzzyLogic".

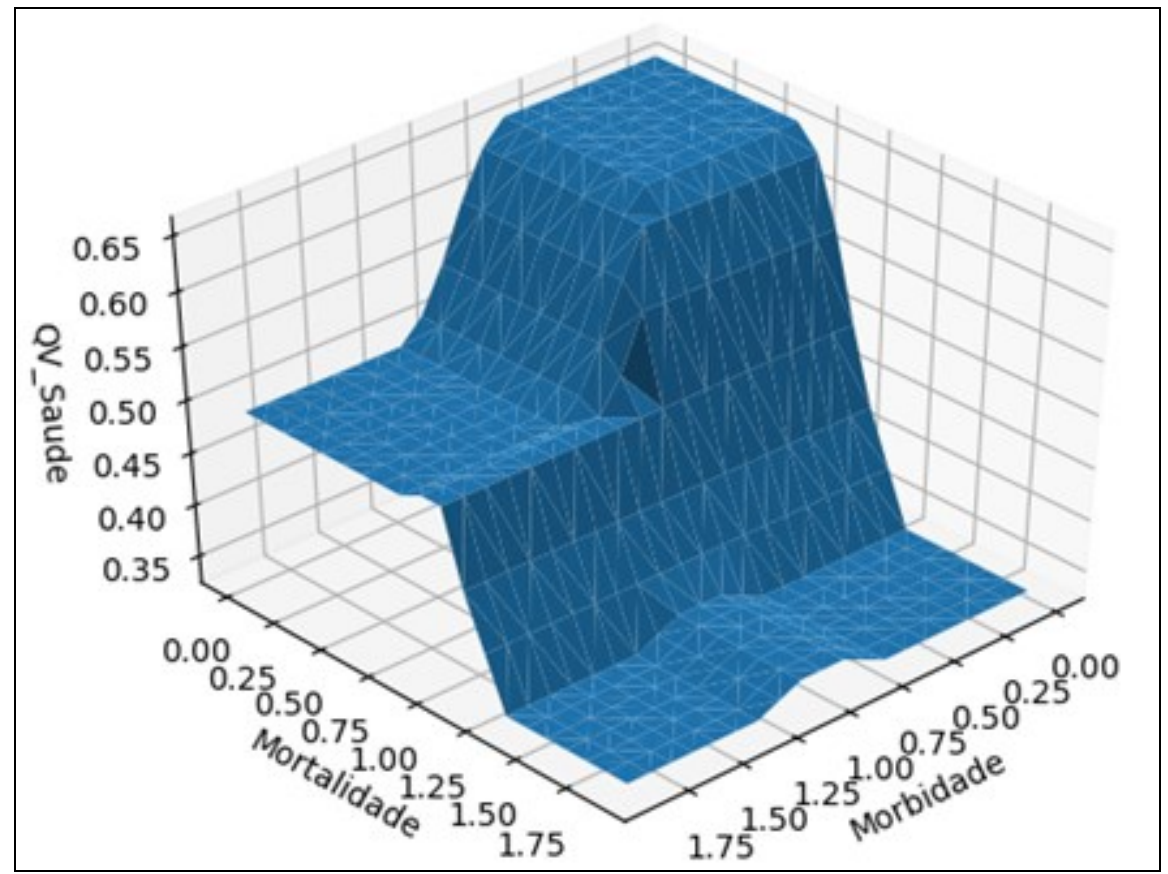


Figura 8 - Idem ao anterior, variando-se os valores de "Mortalidade" e "Qualidade Atendimento", com a variável "Morbidade" fixa em 0,6 , calculados no programa "jFuzzyLogic".



Figura 9 - Idem ao anterior, variando-se os valores de "Morbidade" e "Qualidade Atendimento", com a variável "Mortalidade" fixa em 0,8 , calculados no programa "jFuzzyLogic".






\section{CONCLUSÕES}

O estudo de ameaças limitou-se ao uso de ferramentas qualitativas, considerações subjetivas (com base na experiência dos pesquisadores), informações limitadas acerca da quantidade de variáveis envolvidas, proposição de métodos inovadores, entre outras características já mencionadas (método). Os resultados obtidos também indicam a existência, acima de padrões nacionais e internacionais, de alguns parâmetros ambientais analisados. Os estudos apontaram para a ameaça da exposição da população ribeirinha ao consumo de pescados comprometidos pela poluição (onde a via de exposição dos moradores não foi confirmada no trabalho) e indicam um monitoramento preventivo de vigilância sanitária e ambiental desse pescado, do rio (água e sedimento) e do solo da comunidade.

Com relação aos resultados expostos, é possível concluir que no sistema de saúde da llha não há ameaça à qualidade de vida da população, no que se refere às consultas e atendimentos básicos de saúde. Ponderando-se as formas de exposição da população às ameaças aqui consideradas, presentes na água do Rio Diana, e a partir do relato dos entrevistados, foi possível concluir que entre as formas de contaminação por consumo de peixes (ingestão de contaminantes) ou pelo uso do rio para lazer (contato dérmico e ingestão), a mais provável é a primeira (consumo de peixes possivelmente contaminados). Neste caso, consideramos os metais definidos pela Agência Nacional de Vigilância Sanitária (Anvisa) (Decreto № 55.871/1965 e Portaria $N^{\circ} 685$ ) como padrões para caracterizar as ameaças a que a população ribeirinha está exposta, e neste contexto, nenhum dos metais considerados pela Anvisa indicou concentração acima do estabelecido por ela.

Ainda com relação às análises ambientais, são necessários mais estudos para determinar se os parâmetros "metais dissolvidos em água e em sedimento; HPA em sedimento e parâmetros inorgânicos em água" devem ser considerados como ameaças a Qualidade de Vida da população, visto que parte das amostras apresentaram valores acima do estabelecido pelas legislações nacionais (parâmetros inorgânicos e metais dissolvidos em água; metais dissolvidos em sedimento) e internacionais (HPA em sedimento), porém a via de exposição a estes não foi confirmada durante o período de execução do projeto. Adicionalmente, ainda que as análises ambientais tenham sido feitas seguindo referências bibliográficas conhecidas, não houve o "acompanhamento periódico sazonal", e erros podem estar associados tanto à forma de coleta e ao armazenamento.

Com relação ao modelo Difuso, a análise realizada no tópico de "Qualidade de Vida da Saúde" podese dizer que modelo pareceu ajustado para representar o comportamento da llha neste quesito e foi promissor como indicativo de método para correlacionar variáveis multidisciplinares cujas relações entre as mesmas são complexas.

\section{LIMITAÇÕES DA ANÁLISE:}

A partir da avaliação socioambiental desenvolvida durante o projeto, que identificou fatores de interferência no cotidiano dos moradores da ilha, resultando nas ameaças identificadas. Entretanto, há de se considerar algumas limitações da análise aqui realizada, a saber:

- $\quad$ O estudo desenvolvido buscou identificar as ameaças presentes à comunidade local. Em um processo de análise de risco completo, outras etapas devem ser cumprida para a definição do risco real a que a comunidade está exposta. Posteriormente, sugere-se a proposição das medidas mitigadoras mais efetivas e viáveis, considerando questões como exposição ao risco, frequência, barreiras não identificadas e demais características que não foram aqui analisadas;

- Apesar das vantagens da aplicação do questionário proposto na metodologia, cabe ressaltar as limitações deste procedimento metodológico, sendo que sua validade estatística não foi aqui comprovada, bem como a correlação entre as questões do IBGE e TAUS (2010), além das demais limitações inerentes a este procedimento metodológico.

- $\quad$ Reforça-se que os resultados das análises realizadas podem ter uma pequena margem de erros devido a formas não adequadas de armazenamento da amostra e erros manuais no processo de manuseio do equipamento e da amostra no momento da análise propriamente dita. 
- No caso do llha Diana, a inexistência de demais estudos de caso similares dificulta a aplicação do QCA, mas não invalida sua lógica metodológica. A relação entre as variáveis sociais e ambientais torna-se de difícil validação. Ainda assim, vale a tentativa de aplicação do método, usando os resultados do questionário (respostas acerca da qualidade de vida dos moradores) como um balizador do modelo metodológico construído.

- $\quad$ Outras ameaças socioambientais que não foram estudadas ou identificadas. Ex: questões envolvendo a qualidade do ar, pernilongos (exposição a doenças), resíduos sólidos trazidos pela maré poluindo a llha, entre outros.

\section{AGRADECIMENTOS}

O projeto foi financiado por meio do Programa de Investimento Social Privado da Fundação de Apoio ao Instituto de Pesquisas Tecnológicas - FIPT. Os autores gostariam de agradecer a FIPT, ao Instituto de Pesquisas Tecnológicas do Estado de São Paulo e ao prof. Dr. Ronaldo Torres da Universidade Federal de São Paulo por todo o apoio recebido.

\section{REFERÊNCIAS BIBLIOGRÁFICAS}

ANVISA. Decreto No 55.871/1965. $\quad \mathbf{N}^{\circ}$ Disponível <http://portal.anvisa.gov.br/documents/33916/391619/DECRETO\%2BN\%25C2\%25BA\%2B55.871\%2 52C\%2BDE\%2B26\%2BDE\%2BMAR\%25C3\%25870\%2BDE\%2B1965.pdf/59b8704c-52f4-481d8baa-ac6edadf6490>. Acesso em: 03 de jun. 2019

ANVISA. Portaria $n^{\circ} 685$ - Regulamento Técnico. Princípios gerais para o estabelecimento de níveis máximos de contaminantes químicos em alimentos. Disponível em: <http://bvsms.saude.gov.br/bvs/saudelegis/anvisa/1998/prt0685_27_08_1998_rep.html> <http://bvsms.saude.gov.br/bvs/saudelegis/anvisa/1998/anexo/anexo_prt0685_27_08_1998.pdf>. Acesso em: 03 de jun. 2019.

ATSDR. Toxicological profile for Zinc. Atlanta, GA: U.S. Department of Health and Human Services, Public Health Service, 2005. Disponível em: <https://www.atsdr.cdc.gov/phs/phs.asp?id=300\&tid=54>. Acesso em: 03 de jun. 2019.

BLANCO, M. J.; DEMARCO, L. F. W.; TAKASE, L. S.; JOÃO SOBRINHO, L. A.; SALDIAS, F. I. Análise de riscos socioambientais para a comunidade da llha Diana, Santos/SP: um exemplo de abordagem multidisciplinar. Congresso Brasileiro de Profissionais das Geociências, anais... São Paulo, 2019.

CESAR, A. et al. Ecotoxicological assessment of sediments from the Santos and São Vicente estuarine system- Brazil. Braz. j. oceanogr., São Paulo, v. 54, n. 1, p. 55-63, Mar. 2006. https://doi.org/10.1590/S1679-87592006000100005

CONAMA. RESOLUÇÃO CONAMA $\mathbf{N}^{\circ} 454$, DE $1^{\circ}$ DE NOVEMBRO DE 2012. Disponível em: <http://www.icmbio.gov.br/cepsul/images/stories/legislacao/Resolucao/2012/res_conama_454_2012_ materialserdragadoemaguasjurisdicionaisbrasileiras.pdf>. Acesso em: 24 nov. 2019.

DEMARCO, L. F. W.; BARBOSA, A. M.; BLANCO, M. J.; FONSECA, A. F.; TAKASE, L. S.; JOÃO SOBRINHO, L. A.; SALDIAS, F. I. S. Uso do XRF em amostras de solo da comunidade llha Diana - Santos, SP. $16^{\circ}$ Congresso Brasileiro de Geologia de Engenharia e Ambiental, anais... São Paulo, 2018. https://doi.org/10.22533/at.ed.4421921027

EPA. Cobalt Compounds. $2000 . \quad$ Disponível em: <https://www.epa.gov/sites/production/files/201609/documents/cobalt-compounds.pdf> Acesso em: 03 de jun. 2019

IARC - International Agency for Research in Cancer, 1983. The monographs.In: Evaluation of the carcinogenic risk of chemicals to humans. Polynuclear aromatic hydrocarbons, Part $1-$ Chemical environmental and experimental data, IARC, Lyon, France, 32: 95-451 
INSTITUTO DE PESQUISAS TECNOLÓGICAS DO ESTADO DE SÃO PAULO. Avaliação socioambiental e proposição de medidas mitigadoras para a comunidade caiçara da llha Diana - Santos, SP. São Paulo: IPT, 2018. (Relatório 153.747-205).

JFUZZYLOGIC. Disponível em: http://iFuzzylogic.sourceforge.net/html/index.html, acesso em: 20 de nov. 2017.

MARANDOLA, E.; HOGAN, D. J. As dimensões da Vulnerabilidade. São Paulo em Perspectiva, v. 20, n. 1, p. 33-43, 2006

MARTIN, S.; GRISWOLD, W. Human Health Effects of Heavy Metals. Environmental Science and Technology Briefs from Citizens, 15, 1-6, 2009. Disponível em: $<$ https://www.engg.ksu.edu/chsr/files/chsr/outreachresources/15HumanHealthEffectsofHeavyMetals.p df>. Acesso em: 03 de jun. 2019

NASCIMENTO, I. B.; LARANJA, R. E. P. Uma discussão teórica sobre a análise Socioambiental e algumas contribuições à geografia da saúde. HYGEIA (Revista Brasileira de Geografia Médica e da Saúde),n. 4, v. 7, 2008

QUEIROZ, M. S. M. Hidrocarbonetos Policíclicos Aromáticos em sedimentos de fundo do estuário do Rio Potengi. Região da grande Natal (RN): Implicações Ambientais. Universidade Federal do Rio Grande do Norte, Programa de Pós-Graduação em Ciência e Engenharia do Petróleo, 2011. Dissertação de Mestrado, 99p.

ROMANI, C. 2010. Comunidades caiçaras e expansão portuária em Santos - uma análise histórica do conflito. Revista Científica Integrada - Unaerp Campus Guarujá - Ano 1 - Edição 1 Setembro/2010

STEPHENSON, J. System safety 2000: a practical guide for planning, managing, and conducting system safety programs, 1ed. New York, 1991.

STORI, F.T. 2010. Adaptatividade e Resiliência no Sistema Sociológico da Comunidade Caiçara da Ilha Diana. Tese de Doutorado em Ecologia e Recursos Naturais da Universidade Federal de São Carlos. 241p.

TORRES, R. J.; VIANA M. A.; RIOS, L. G. Caracterização da Ilha Diana: Comunidade Tradicional. 25 pag., 2016.

US DEPARTMENT OF HEALTH AND HUMAN SERVICES et al. Toxicological profile for polycyclic aromatic hydrocarbons (PAHs). Atlanta: Agency for Toxic Substances and Disease Registry, 1995. 


\section{ANEXO I}

Questionário APP: Avaliação preliminar de perigos/ameaças

Identificação da residência (mapa):

Nome do entrevistado:

Idade do entrevistado:

Tempo de residencia na ilha:

Quantidade de moradores na mesma casa:

Grau de parentesco dos seus familiares morando na casa:

\section{Saúde}

1. Você utiliza o posto de saúde da ilha? Qual foi a última vez?

2. Em sua opinião o horário disponibilizado pelo posto é suficiente? Senão, qual a sugestão?

3. Existe alguma dificuldade em encontrar funcionários no posto ao precisar de atendimento (enfermeiros, médicos)? Você considera a quantidade atual suficiente?

4. O posto disponibiliza consultas ou apenas pronto atendimento?

5. Você acha o tempo de atendimento adequado? Resolveu seu problema?

6. Quanto tempo em média demora em se agendar uma consulta?

7. Você consegue adquirir gratuitamente todos os remédios que necessita no posto na quantidade desejada?

8. E em relação aos atendimentos em emergência (acidentes, medicamentos e equipamentos necessários para alguma situação de emergência, picadura de animais, ou outros), você ou algum membro da sua familia já precisou de algum atendimento? A necessidade foi resolvida dentro da ilha?

9. Existe transporte para fora da Tha em casos de emergência (em diferentes horários)? Como ele funciona?

10. Para alguma das necessidades aqui mencionadas, foi necessário sair da ilha?

11. Você ou algum membro da sua familia se encontra em alguma situação das listadas abaixo?

\begin{tabular}{|l|l|l|}
\hline & Entrevistado & \\
\hline Diabetes & & \\
\hline Hipertensão & & \\
\hline Obesidade & & \\
\hline Problemas cardíacos & & \\
\hline Câncer & & \\
\hline Tuberculose & & \\
\hline Desnutrição & & \\
\hline Asma & & \\
\hline Alzheimer & & \\
\hline Parkinson & & \\
\hline Alcoolismo & & \\
\hline Dengue & & \\
\hline Febre amarela & & \\
\hline Leptospirose & & \\
\hline Chikungunya & & \\
\hline Outros & & \\
\hline
\end{tabular}

\section{Existência e aderência a exames preventivos e campanhas;}

12. Você ou algum membro da sua familia faz exames preventivos aqui dentro da Tha fornecidos pela prefeituraposto (Ginecológicos, mama, etç)? Com qual frequência?

13. O posto fomece métodos contraceptivos?

14. Você ou algum membro da sua familia já participou de alguma campanha de vacinação, educação sexual ou contra algumas das doenças citadas? 
Saúde bucal;

15. Você e seus familiares se consultam com algum dentista? Dentro ou fora da tha?

16. Com que frequência você e familiares vão ao dentista?

Eficiência de atendimento médico na ilha (para diferentes situações e doenças);

17. Como você considera em geral os atendimentos médicos na ilha (consultas, remédios, campanhas e posto de saúde)? $(B=$ bom, $M=$ médio, $R=$ ruim)

18. $\mathrm{E}$ os atendimentos de emergência? $(B=$ bom, $M=$ médio, $R=$ ruim)

\section{Infra-estrutura}

19. Sua familia é moradora permanente da Ilha?

20. Você mora sozinho ou com a sua familia ou em mais de uma familia, na mesma casa?

21. A sua casa é própria, alugada, ou outra forma?

22. Quantos cômodos existem na moradia? (Inclusive banheiro e cozinha)

23. Quantos dormitórios existem na casa? Quantos,moradores por quarto?

24. Existe energia elétrica no domicilio? Rede pública ou gerador (próprio ou da Ilha)?

Entrevistador: anote o material predominante nas paredes extemas (Alvenaria aparente ou pintada, Madeira ou outro)/ piso (chão batido, concreto, cerâmico, madeira ou outro )/ telhado (laje, telha cerâmica, metálica ou "Etemit" (amianto) ou outro)

\section{Saneamento (água potável, resíduos, esgoto)}

25. A casa tem banheiro próprio? Localiza-se na casa ou no terreno?

26. Onde o esgoto é lançado?

27. Existe água encanada da rede pública no domicilio? Se não, de que forma?

28. Qual a frequência do lixeiro? Quantos sacos são gerados?

29. Cite os principais materiais descartados (plásticos, vidros, metais, orgânicos, outros)

30. Como você avalia os serviços de saneamento da Ilha (água, resíduos, esgoto)? $(B=$ bom, $M$ $=$ médio, $\mathrm{R}=$ ruim)

\section{Comunicação}

31. Você tem acesso a algum dos meios de comunicação listados abaixo? Cite a qualidade $(B=$ bom, $\mathrm{M}=$ médio, $\mathrm{R}=$ ruim)

Internet ( ) ) telefone fixo residencial ( ), celular ( ), telefone público ( ), televisão ( ), rádio ( ), outro ( )

\section{Lazer}

32. Quais tipos de atividades de lazer sua familia pratica na Ilha? (ex: Aulas de dança, oficinas de pesca, aulas de música, aulas de lutas, futebol, etc)

33. Você julga satisfatório? ( $B=$ bom, $M=$ médio, $R=$ ruim) Escolaridade

34. Quais outras atividades você gostaria que fossem desenvolvidas aqui dentro da Tha?

\begin{tabular}{l|l|}
\hline Grau de parentesco e idade (anos) & Grau de escolaridade* \\
\hline & \\
\hline & \\
\hline \multicolumn{2}{|c|}{} \\
\hline *=analfabeto, creche (até 6 anos), fundamental incompleto/completo (7 a 14), médio \\
incompleto/completo (15 a 17), superior incompleto/completo (maior de 17)
\end{tabular}


35. Frequenta instituição de ensino dentro ou fora da ilha? Pública ou particular?

36. Qual o tempo de deslocamento até a escola (se fora da ilha)?

37. Qual sua avaliação do ensino na ilha? $(\mathrm{B}=$ bom, $\mathrm{M}=$ médio, $\mathrm{R}=$ ruim)

\section{Segurança pública}

38. Você já ficou sabendo de algum caso de violência na ilha? Se sim, de que tipo (mortes, brigas, roubo, furto, violência doméstica ou sexual)?

39. Quando ocorreu o último caso? (até 1 ano, entre 1 e 5 , ou mais de 5 anos)

40. Houve atuação da polícia ou não?

41. O infrator é da ilha ou de fora?

42. Você e seus familiares sentem-se seguros na ilha? $(B=$ bom, $M=$ médio, $R=$ ruim)

\section{Parâmetros econômicos}

43. Quantos dos seus familiares trabalham? Quais as atividades? Registrado ou não?

44. Possui outras formas de complementação de renda? (segundo trabalho, trabalho temporário, aluguel, contribuição de programa social, aposentadoria, negócio próprio, "bicos", etcl)

45. Qual a renda mensal da sua familia (moradores da mesma casa)?

(. )até RS1mil, ( ) de $1 \mathrm{mil} \mathrm{a} 3 \mathrm{mil}$ ( ) de 3 a $5 \mathrm{mil}$, ( ) acima de $5 \mathrm{mil}$, ( ) não informou

46. Qual a despesa mensal da sua familia (moradores da mesma casa)? (alimentação + transporte + saúde + educação + segurança + lazer)

(. )até RS1mil, ( ) de $1 \mathrm{mil} \mathrm{a} 3 \mathrm{mil}$ ( ) de 3 a $5 \mathrm{mil}$, ( ) acima de $5 \mathrm{mil}$, ( ) não informou

47. Quantas horas semanais são destinadas ao(s) trabalho(s)?

48. O trabalho é realizado dentro da Iha Diana, nestes casos, em quais atividades? Se não, em qual município trabalha? Qual o tempo de deslocamento até o trabalho (ida e volta)?

49. Você ou algum membro da sua familia já viveu de alguma atividade na Tlha? Quais atividades? Por que deixou de atuar?

50. Você seria a favor da exploração do turismo na ilha como forma de obter renda para a comunidade?

51. Em sua opinião, o que poderia ser feito para a geração de renda dentro da ilha?

52. Você consome algo produzido na ilha? $\mathrm{O}$ que? (pão, peixe, marisco, caranguejo, frutas, hortas, etc)

\section{Sentimento de pertencimento}

53. Você tem familiares que saíram da ilha (moradores) nos últimos 5 anos? Quantos? Quais motivos?

54. Quais são os pontos positivos de morar na Tha?

55. Quais são os pontos negativos de morar na Ilha?

56. Você se mudaria da Ilha? Se sim, por quais motivos?

57. O que te faz permanecer na ilha?

58. Das principais dificuldades citadas, quais mais afetam seu dia a dia?

\section{Comentários adicionais.}

